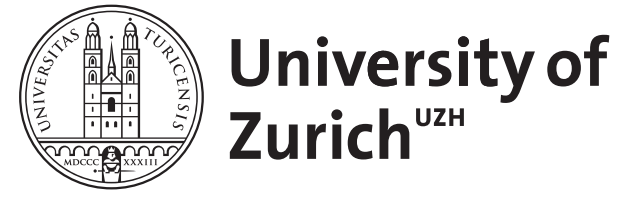
Archive

University of Zurich

University Library

Strickhofstrasse 39

CH-8057 Zurich

www.zora.uzh.ch

Year: 2007

\title{
Will the Bali spirit point the way?
}

Michaelowa, Axel

DOI: https://doi.org/10.1007/s10272-007-0224-9

Posted at the Zurich Open Repository and Archive, University of Zurich

ZORA URL: https://doi.org/10.5167/uzh-156413

Journal Article

Published Version

Originally published at:

Michaelowa, Axel (2007). Will the Bali spirit point the way? Intereconomics, 42(5):234-235.

DOI: https://doi.org/10.1007/s10272-007-0224-9 


\section{Will the Bali Spirit Point the Way?}

In the first two weeks of December, more than 10,000 representatives of countries, NGOs and lobby groups will meet in Bali for the annual Conference of the Parties of the UN climate negotiation process. As in the course of 2007 public and media interest on climate change has reached an all-time high, the world is eagerly awaiting the decisions of the Bali conference. Politicians and researchers have already set the scene. The EU declared that it would strive for a $30 \%$ greenhouse gas reduction by the industrialised countries by 2020 and has agreed on far-reaching renewable energy and energy efficiency targets to reduce its own emissions. The Intergovernmental Panel on Climate Change published its Fourth Assessment Report with the statement that the warming of the climate system is unequivocal. It finds that widespread changes in precipitation and aspects of extreme weather have been observed and projects a warming of about $0.2^{\circ} \mathrm{C}$ per decade for the next two decades. In order to stop the temperature increase at about $2^{\circ} \mathrm{C}$ above pre-industrial levels, which is generally acknowledged to be a level where the impacts of warming remain manageable, the peak of global emissions should be reached no later than 2015. During the negotiation of the policymakers summary of the report, the Chinese delegation tried to delete this statement. But, tellingly, China did not find sufficient support by other countries for this request ... Within the USA, the post-Bush era is announcing itself with a flurry of greenhouse gas emission reduction bills being debated in Congress and an increasing number of state-based emissions trading and renewable energy initiatives. At the level of the G8, the Heiligendamm Summit rallied support for an early deadline for the negotiations on the post-2012 climate policy regime. And in late September, over 80 heads of state gathered at the UN headquarters for a one-day discussion on climate policy. Never before has climate policy dominated political discourse in the way it does in 2007. Even countries like Australia that have not ratified the Kyoto Protocol are calling for a Bali mandate. This momentum has to be harnessed before the window of opportunity closes when immediate economic or political challenges sideline climate policy.

Increasingly, the climate policy world is differentiated into the following four packages: adaptation, mitigation, technology and financing. The first package caters for the interests of developing countries, the second for environmentalists and the EU, the third serves to bring the USA back to the negotiating table and the fourth is the umbrella covering the other three. Adaptation is a difficult topic given that it is inherently difficult to evaluate the success of adaptation measures - the absence of catastrophes due to meteorological extremes. Many proposed adaptation measures are in fact activities to improve the development status of a population. But adaptation cannot shoulder the tasks of development policy. It is thus challenging to develop incentive-compatible mechanisms for the allocation of adaptation funding. Experiences made so far with the decision-making procedure and the actual distribution of such funds by the Global Environment Facility are not encouraging. Finding equitable ways of raising adaptation finance and spending it wisely will be a looming challenge during the negotiations.

Regarding mitigation, the EU target declaration has catalysed substantial progress. The Vienna meeting of the UNFCCC in August mentions reductions of 25-40\% from 1990 levels by 2020 for Annex B countries as an "important contribution to overall global efforts required" to avoid dangerous climate change. This defines an important guardrail leading towards serious reductions. The willingness to discuss such ambitious numbers has been bolstered by the astonishing results of the Clean Development Mechanism. Within only three years, it has mobilised over 2000 projects that forecast the generation of over 2 billion emissions credits. While the CDM faces challenges with regards to its environmental 
credibility which have to be resolved to make it a pillar of the post-2012 climate policy regime, it is now universally embraced by industrialised and developing countries alike.

A key stumbling block is the continuing unwillingness of developing countries to discuss the expansion of legally binding emissions commitments. However, it should be self-evident that countries that become members of institutions of the industrialised world such as the OECD or the EU take up emissions commitments as part of the "acquis communautaire". Moreover, the explosion of oil price revenues has propelled some countries in the Middle East to the status of the most wealthy and modern places on the planet. They should also take up their share of the responsibility. However, no one can seriously expect a country like India, which has only $25 \%$ of the world's average per capita emission, to take up a commitment. China, however, whose emissions rose by 2.5 billion t $\mathrm{CO} 2$ in only four years, has now surpassed the global average per capita emission and can no longer argue that it would be premature to get involved. To save face, commitments could be limited to sectors and could be non-binding but still allow emissions trading. That this is an uphill battle is shown by the statement of former Indian negotiator Ghosh, who wants to avoid the commencement of any process leading to uncompensated greenhouse gas constraints, and retain competitive advantage in trade.

Technology development is a package where we are still waiting for a breakthrough. Most industry representatives and even some environmental NGOs have set their bet on geological carbon sequestration and storage. Whether this bet is safe or a costly detour remains to be seen; the challenges of non-permanence should not be dismissed lightly. Other technologies like nuclear and liquid biofuels are more controversial. Surprisingly, a key candidate - parabolic trough solar power - has still not garnered the political and industrial support necessary to repeat the success story of wind power. Less politically visible but even more effective would be a strong energy efficiency technology diffusion drive. Further ideas would be a venture capital fund and the setting up of international research centres on the model of the international crop research institutions.

Financing has been the Achilles heel of climate policy for more than a decade. According to a UNFCCC study, global additional investment and financial flows of \$200-210 billion will be necessary in 2030 to return global greenhouse gas emissions to current levels. Recently, more and more mainstream financial institutes are directing funds into low-emission technologies, particularly in the context of the CDM. But mainstreaming of climate concerns into energy finance is still far away, as the case of the World Bank shows. The power of financing to avoid deforestation has now been realised by a majority of countries and stakeholders, even those that strongly opposed such incentives only a few years ago. An agreement on a new deforestation-related market mechanism would be an opportunity to rectify the mistake made in 2001 when deforestation avoidance was excluded from the CDM.

Carbon markets will play a crucial role in linking the mitigation, financing and technology packages. This is succinctly stated in the summary of the "midnight sun dialogue" of environment ministers convened by Sweden: "Widespread use of low-carbon technologies can hardly be achieved without setting a price on carbon emissions. Access to and flexibility in the carbon markets ensure the most cost-effective implementation of commitments to limit and reduce emissions, as well as to mobilise resources to provide incentives to developing countries." Let us hope that the Bali spirit will bridge the interest gap between North and South. Economically efficient instruments are available to take up the challenge of serious greenhouse gas reductions.

Axel Michaelowa

University of Zurich, Switzerland 